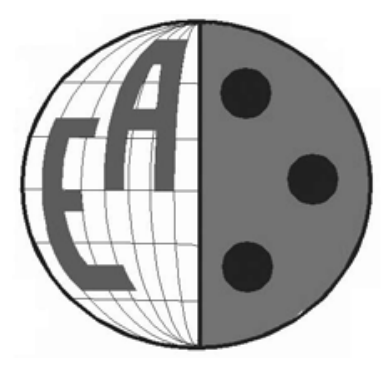

Athens, September 2007

Organized by the Benaki Phytopathological Institute, Kifissia, Attica, and the Agricultural University of Athens

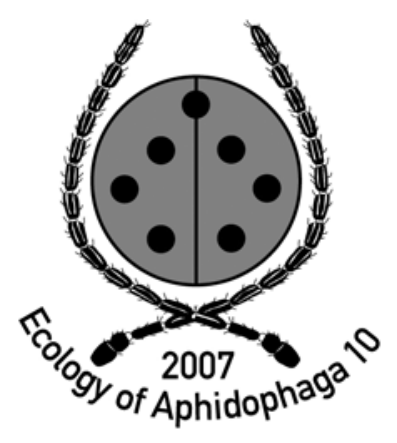

\title{
Editors :
}

E.W. Evans, I. Hodek, N.G. Kavallieratos, E. Lucas,

M. Mackauer, J.P. Michaud 


\section{PREFACE}

The series of symposia known as Aphidophaga began with a meeting in 1965 in the former state of Czechoslovakia. At that time, opportunities for eastern European scientists to travel to international conferences were greatly limited by the "iron curtain" of the Soviet Union. The symposium was originally organized by Czech entomologists as a means of sharing current research on the ecology of aphid natural enemies with their counterparts from western countries. Notable among the founders is our own executive editor of EJE, Ivo Hodek who convened the first two symposia, as well as number 9 in České Budějovice. Ever since the beginning, the series has served as forum for the exchange of ideas and research on the fascinating subject of aphidophagous organisms, unified by the simple premise that the habit of consuming aphids leads to the evolution of unique life histories and ecologies.

The $10^{\text {th }}$ meeting of Aphidophaga was hosted in Athens, Greece by our colleagues at the University of Athens under the capable leadership of Nickolas Kavallieratos. There were 80 registered participants from 23 countries. Honorable mention must be given to Helmut van Emden, the only participant to have attended not only the very first Aphidophaga, but every single one since 1965! The symposium was memorable, not only for the many excellent scientific presentations, but also for our visit to the venerable Acropolis and the gracious hospitality of our Greek hosts. Following a presentation by Jacques Brodeur on behalf of the International Organization of Biological Control, our membership supported a proposal to renew our affiliation with this organization as an official working group. The IOBC generously provided a total of six grants to student members that covered a significant portion of their travel costs to attend the meeting.

The membership supported a motion to hold the next Aphidophaga symposium in Perugia in central Italy in the fall of 2010. If you would like to be added to the electronic mailing list for news and updates on Aphidophaga 11, or if you are a member who has recently changed your email address, please send an email to <jpmi@ksu.edu> with "Aphidophaga" in the subject line.

\section{J.P. Michaud}

Chair, Aphidophaga 11 

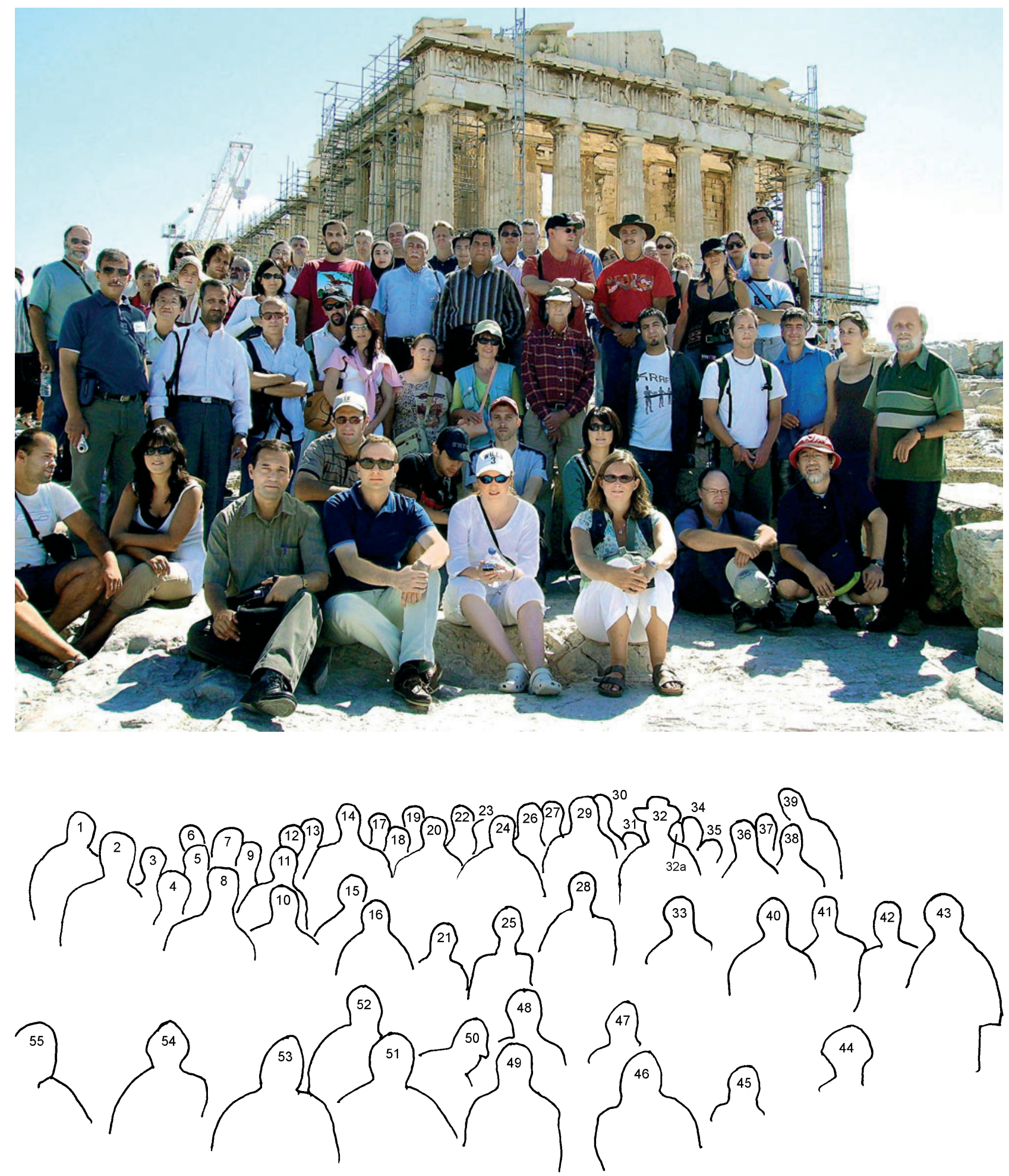

1 - Gerry Michels; 2 - S. Moharramipour; 3 - Judy Michels; 4 - K. Ito; 6 - Susan Moser; 7 - Nick Bergvens; 8 - A.A. Talebi; 9 Mark Brown; 11 - Xavier Pons; 12 - Oldřich Nedvěd; 13 - Ted Cottrell; 14 - Ezra Schwartzberg; 17 - Peter Brown; 18 - T. Alawi's daughter; 19 - John J. Sloggett; 20 - Thabet Allawi; 21 - Aurelia Ferrer; 22 - Kris Giles; 23 - G.M. Wu; 26 - Eduardo Hatano; 27 - Joeren van Schelt; 28 - Edward W. Evans; 29 - Michael Brewer; 30 - Vlastimil Křivan; 31 - Olga Ameixa; 32 - J.P. Michaud; 32a - Helmut F. van Emden; 33 - V. Žikić; 34 - Maryse Barrette; 36 - Audrey Grez; 37 - Sima Rasekh; 39 - Arash Rasekh; 41 - Jacques Brodeur; 42 - Josee Doyon; 43 - Pavel Kindlmann; 44 - Naoya Osawa; 46 - Helen Roy; 47 - Yuki Kajita; 48 - Bruno Fréchette; 49 - Remy L. Ware; 51 - Nickolas Kavallieratos; 53 - Yaghoub Fathipour. 